\title{
Applying an understanding of farmers' values and goals to their farming styles
}

\author{
T.G. PARMINTER and A.M.L. PERKINS \\ AgResearch, Ruakura Agricultural Research Centre, PB 3123, Hamilton
}

\begin{abstract}
A study was undertaken to identify the relationships between farmers' values and their farming goals. Fifty goals were first identified from interviews with 20 farmers in the Waikite Valley. In a further survey of 1100 farmers in Hawke's Bay, King Country and Taranaki, respondents were asked to score the importance of each of the goals. The survey had 680 responses. Cluster analyses of the scores from the survey were used as the basis for developing 10 goal categories. The most important category of goals for $43 \%$ of the farmers was that related to maximising farm production and profitability. These goals could be associated with people who put a priority upon values which emphasised individual success. The environmental goal category was prioritised by $7 \%$ of farmers, with values emphasising the welfare of others and the management of natural resources. The implications of this study for consultancy strategies are that although most farmers ranked their production goals very highly, they also wanted to realise a whole range of other goals (often including the environment), all of which needed to be addressed. Policy agencies associated with environmental management to implement the Resource Management Act (1991) should develop strategies of working with farmers that account for the multiple goal structure of farming styles. This can be done by providing farmers with management options that can be used to satisfy a number of farming goals. The availability of such management options is likely to encourage greater levels of voluntary change.
\end{abstract}

Keywords: farming styles, goals, planning, values

\section{Introduction}

Farmers, like all people, have values ${ }^{1}$. Values are the framework through which people evaluate their own lives and the lives of others. Farmers express values through implementing a range of farming goals ${ }^{2}$ (Gasson 1973). In this study, the links between farmers' values and their farming goals (both economic and noneconomic) were examined by the authors to provide a categorisation $(\operatorname{taxonomy})^{3}$ ) of goals for further research.

The values used in this project were identified by Shalom Schwartz (Schwartz 1992) and came from a study of people throughout the world. Values are stable and used by people to select and evaluate behaviour and events. Farmers could express their values through their farming goals and objectives, and these last two would be more context specific and tangible than their underlying values (Parminter et al. 1993).

Schwartz's values were:

1. Self-direction choosing, creating and exploring to achieve independence in thought and action.

2. Stimulation having a varied and exciting life with lots of novelty and challenge.

3. Hedonism seeking pleasure and sensuous gratification to enjoy life

4. Achievement personal success through demonstrating competence according to social standards

5. Power attaining social status and prestige, getting access to and control of people and resources

6. Security obtaining safety, harmony, and stability in society, in relationships with others, and with self.

7. Conformity exercising self-restraint in actions, inclinations, and impulses likely to upset, or harm others, and violate social norms.

8. Tradition building respect, commitment and acceptance of the customs and ideas found by sharing cultures and religions.

9. Benevolence preserving and enhancing the welfare of people that provide frequent personal contact.

10. Universalism understanding, appreciating, tolerating and protecting the welfare of all peoples, and of nature.

Although farmers' goals have been known to be related to their styles of management for some time

1 Values are relatively stable attitudes towards abstract goals or endstates for human existence.

2 Goals are considered to be specific endstates or outcomes toward which people held positive attitudes. Unlike values, goals tend to be context specific.

3 A classification of concepts based upon similarities in empirically obtained data. 
(Gasson 1973; Fairweather \& Keaton 1994), previous studies have not examined their relationship with more underlying and stable values. An understanding of people's goals has been used to predict their behaviour (Eagly \& Chaiken 1993). Such understandings could be applied by farmers and their advisors in consultation, to improve the appropriateness and efficiency of advice. In this study, a categorisation of farming goals was linked to underlying values and used to predict farm management styles.

\section{Methods}

The study was carried out in two stages; the first to identify farmer goals, and the second to obtain farmer ratings for the importance of each goal. In the first stage, 20 farmers in the Waikite Valley near Rotorua were interviewed using semi-structured questioning to identify the range of goals. From these interviews a list of 50 statements defining each goal was developed. Clarity of descriptions and their relationship to Schwartz's values were checked by an independent assessment carried out by five researchers associated with the project.

In the second stage, a postal survey was made of 1137 farmers on the electoral rolls for the Hawke's Bay, King Country and Taranaki regions, to understand and test the relationships between goals. The farmers contacted had been stratified according to region, and were randomly selected. We received 680 (50\%) completed responses. Respondents could add extra goals, to those supplied, if they wanted to. However, no new material was provided in this way. The survey had questions about demographic variables (e.g., farming enterprise type, farmer age) and two questions in which respondents were asked to score the importance of the supplied goals on a 1-20 scale (20 was most important). The goal scoring results are reported in this paper.

An incomplete block design using 40 different questionnaires was used to reduce respondent burden, so that each respondent only had 20 (instead of all 50) goals to score. Four types of cluster analyses were carried out: median sort, single linkage, group average, and complete linkage; the common elements apparent in all these approaches at the $65-75 \%$ level are reported in this paper.

When they had been returned, the results were statistically analysed to identify:

- which goals could be grouped into categories with similar scoring patterns, from cluster analyses;

- the best goal statements for identifying farmer goal preferences, from the statement with the highest correlation with the others in their category;
- the rank ordering of goals, from their relative scores; - the relationships between goals and values, by measuring the correlations of the scores for goals assigned to each type of value.

\section{Results}

In Table 1 are shown all the goals identified from the Waikite Valley interviews, and the categories for them (Business ....... Off-farm Interests) developed from carrying out the cluster analyses of the survey results. The first row in the table is the mean score (out of 20) the farmers had for each farming goal category. The scores ranged from a low of 9.4 to a high of 13.9. The similarity in the scoring is indicative of the farmers' consistent support for all the goals that they assessed in the study. The lowest scoring goal was "having the approval of parents or older people" which scored 5.2, and the highest was "ensuring future financial security" which scored 16.6.

The second row in Table 1 contains the mean rankings of each goal category (based upon their relative scores). The poorest possible ranking is 10 . The third row in the table is the proportion of farmers who ranked that farming goal category highest overall. On average the highest ranked goals were those associated with farm production and profitability. Production goals were the most important goals for $43 \%$ of farmers. Less than $10 \%$ of farmers had their highest goals associated with the environment, although most farmers ranked environmental goals relatively highly. No farmers put community goals first.

In Table 1 each goal is listed within each of the categories, from the goals scoring highest at the top of the table to the goals scoring lowest at the bottom. Underneath the table are listed the goals which were not statistically associated with any of the categories listed above. These excluded goals are listed from left to right in descending order of their scoring by farmers. Although these goals were still important to farmers, their pattern of scoring was unrelated to the categories used in the rest of the table. The goal statements underlined in the table are the key goals in each category which in the cluster analyses were the most discriminating amongst that whole category of goals. For instance, in the category of Business goals, the farmers' scores for "building a valuable business" can be used to provide an estimate of the scoring for any of the other Business goals. Used in this way, the key goals explain $46 \%$ of the scoring of all the goals in the table.

In Table 1 each goal has a superscript to indicate which value category of Schwartz they relate to. The value labels are listed under the table and were further described earlier in this paper. 


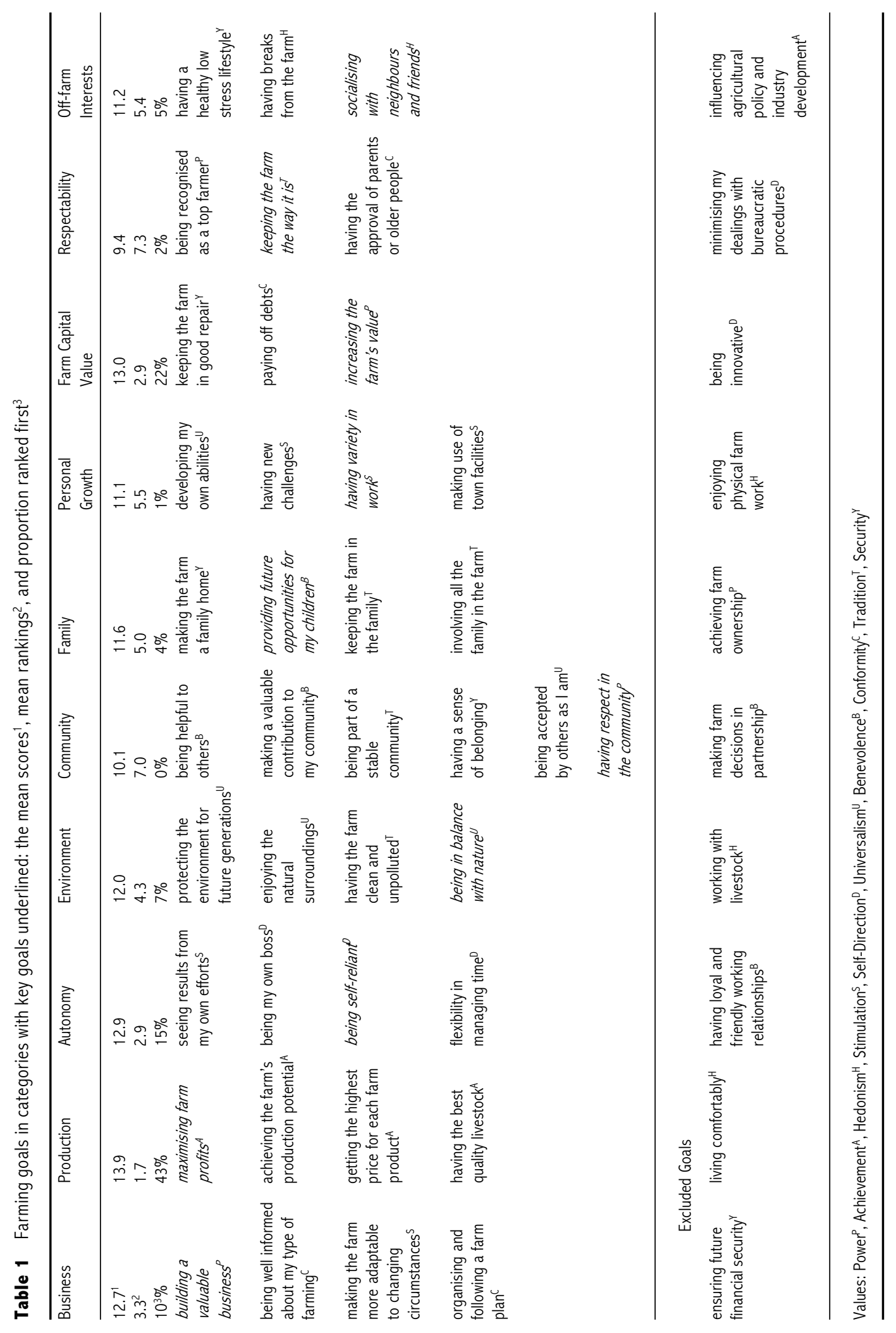


In Figure 1 is shown typical changes in the ranking of farmer goals. The proportion of farmers with goals at each ranking (from their highest ranking to their lowest ranking) followed three different patterns. The figure fits stylised curves to actual data points, but could not be statistically derived because of insufficient data from the incomplete block design. Farmers who gave a high ranking for goals associated with production, autonomy, capital, and business tended to have a low ranking of goals associated with personal growth, community, and respectability. The

Figure 1 Typical relationships between the ranking of farmer goals

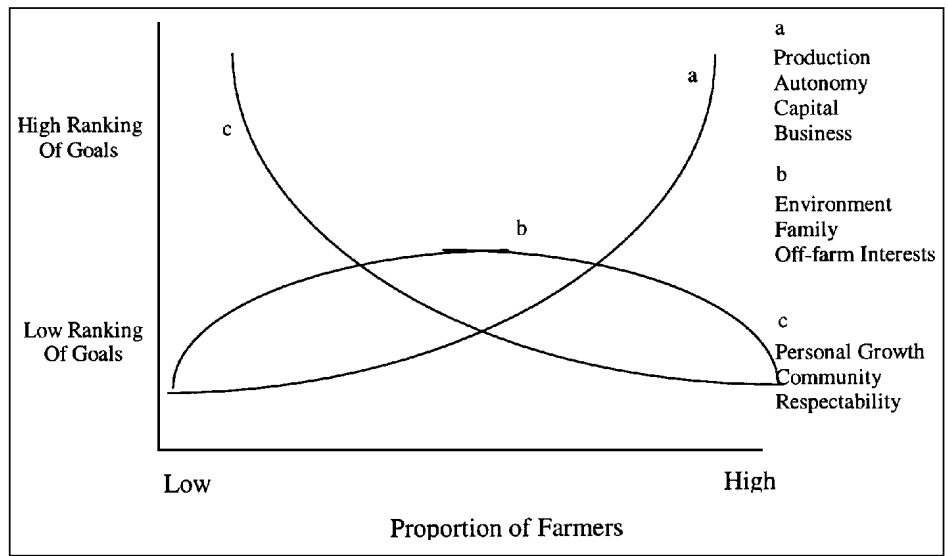
reverse also applied. Goals associated with the environment, family, and off-farm interests tended to have a similar ranking for most farmers.

\section{Discussion}

Farmers' management styles are influenced by their goals. Management styles have been described as the priorities farmers have for strategic use of limited resources: social, labour, economic and natural (Fairweather \& Keating 1994). Much existing literature describes management styles in terms of farmer's orientations towards business practices (Fairweather \& Keating 1994). Yet even financial goals have been shown in this study to vary in their intent, depending upon the values they are associated with. For instance "maximising farm profits", "providing future opportunities for my children", and "paying off debts", are associated with achievement, benevolence and conformity values. Agencies working with individual farmers to develop strategies for implementing farmer goals, will also be interested in whether the related management styles are likely to encourage or limit opportunities for change. Resource managers may be wanting farmers to join landcare groups to learn about ways of addressing community environmental concerns. A description of management styles can also be used to indicate the level of interest that people may have in off-farm priorities and community activities.

In the following discussion the interpretation of farmer values is based upon the work of Shalom Schwartz. From the results of our surveys, Power and Achievement values appear to be important to many of the farmers surveyed and were expressed in various ways in different aspects of farming life. Goals associated with these values were the key goals for Business, Production, and Farm Capital Value categories.

People with Power and Achievement values can be motivated to pursue their own personal interests even if they know other people or the environment can be disadvantaged.

In contrast, people in this survey expressed their Universalism and Benevolence values mainly through environmental and community goals. People with these values were considered by Schwartz to be more likely to transcend selfish concerns and promote the welfare of others and the natural world around them.

The goals associated with Hedonism values were either clustered into "off-farm interests" or else isolated from other clustered goals. Like Power and Achievement, Hedonism values are considered to be more focused upon self. In this study they were most often associated with people with off-farm interests. People with hedonistic values are likely to be less interested in being competitive, and limiting the amount of change in their lives than people with either power or achievement values. Therefore they might be more open to modifying their existing farming practices. People who consider stimulation and self-direction values highly were likely to emphasise goals for Personal Growth or Autonomy. They could be considered to be relatively open to change. Farmers that put a lot of emphasis upon goals from Farm Business, Respectability, Farm Capital Value, and Family categories with conformity, tradition, and security values will tend to be less open to change than other farmers.

\section{Conclusions}

Farmers express their values through a range of individual farming goals. Some of these fit categories of goals that can be evaluated in a similar way for their effects upon farm management styles. Farmers and their 
advisors (e.g., consultants and resource managers) who can clarify and reflect upon values and goals may find planning and decision making easier.

Farm consultants should be identifying the full range of goals that farmers wish to address before setting management priorities. They also should consider their client's underlying values, and how their values interact in the expression of farming styles.

Few of the farmers considered their environmental goals to be their most important. Therefore resource managers should encourage the use of management practices for environmental enhancement that satisfy a range of farming goals, if they want them to be widely taken up (Parminter et al. 1996). People with important environmental or community goals are the ones likely to be found in landcare groups, other farmers are more likely to act individually.

\section{ACKNOWLEDGEMENTS}

Thank you to the many farmers involved in the surveys. We hope that answering our questions encouraged you to reflect upon the rewards of being farmers. We appreciated the contributions made by Martin Upsdell, Mark Paine, Bruce Thorrold, Greg Lambert, Peter Moore, and Gavin Sheath, also Jenny Moore, and Moana Petre.
The study was funded by the Foundation of Research Science and Technology and AgResearch as part of a programme into the Management of Hill Country Catchments.

\section{REFERENCES}

Eagly, A.H.; Chaiken, S. 1993. The psychology of attitudes. p. 186. New York, HBJ.

Fairweather, J.R.; Keating, N.C. 1994. Goals and management styles of New Zealand farmers. Agricultural systems 44: 181-200.

Gasson, R. 1973. Goals and values of farmers. Journal of agricultural economics 24 (3): 521-542.

Parminter, T.G.; Wedderburn, M.E.; Carter, J.C. 1993. Waikato regional workshops on sustainable agriculture: A partnership approach by Federated Farmers, AgResearch, and Environment Waikato. Hamilton, AgResearch.

Parminter, T.G.; Wedderburn, M.E.; Spijkerbosch, P.J. 1996. The importance of a participatory approach to resolving issues of sustainable agriculture. Proceedings of the New Zealand Grassland Association 57: 15-20.

Schwartz, S.H. 1992. Universals in the content and structure of values: theoretical advances and empirical tests in 20 countries. Advances in experimental social psychology 25: 1-65. 
